\section{The role of the under-layer in the coloured perception of gildings in mediaeval mural paintings}

\author{
Aurélie Mounier, Floréal Daniel \\ Centre de Recherche en Physique \\ Appliquée à l'Archéologie - CRPAA, \\ Institut de Recherche sur les \\ Archéomatériaux - IRAMAT, Université \\ de Bordeaux/CNRS, 33607 Pessac, \\ France
}

\section{Abstract}

A study of the gildings used in mural paintings from the $12^{\text {th }}$ to $16^{\text {th }}$ century showed rather limited types of application techniques (essentially mixtion techniques, but also in rare examples distemper techniques) and a higher variety of employed metals. Samples have been taken off from mural paintings in the southwest of France as in the Bordeaux Cathedral, Meyrals Castle, Ste-Marie Church of Audignon. Samples analyses have been carried out by scanning electron microscopy coupled with an energy dispersive X-ray analysis system, Raman spectroscopy and Fourier transform infrared spectroscopy. Depending on the metal used for the gilding, the under-layer could be different in terms of material and colour. Under the gold leaves, the layer is usually red or yellow. That can be explained by the absorption properties of light by the gold leaf. Under tin leaves, which are thicker and opaque, the usefulness of the under-layer is less obvious. An experimental study illustrates the role of the coloured under-layer.

\section{Introduction}

Gilding was a common practice in Romanesque wall paintings. Ancient gildings remnants were recently discovered (gold, silver, and tin) in numerous sites (Mounier et al., 2011).

Often, bad conservation conditions provoked the loss or the metallic leaves alteration. Hygro-thermal variations, architectural modifications or inappropriate interventions weakened the painting layers and generated the degradation of these metallic decorations. Consequently, in most of the mural paintings, only the under-layer of the metallic leaf remains in situ (Daniel and Mounier, 2010). This coloured layer is constituted of pigments and of the organic binders which allows the adhesion of the metal leaf. This under-layer can play a pivotal role on the gold and gildings perception.

A description of the gilding techniques from Antiquity to nowadays can be found in ancient treatises (Pline, $1^{\text {st }}$ century; Theophile, $12^{\text {th }}$ century; Cennini, 14 ${ }^{\text {th }}$ century). Two techniques are mainly mentioned: i) the distemper gilding where the organic binder is composed of Arabic gum or, more often, of a proteinic glue type (from skin, nerve, bone, etc.); ii) the mixtion gilding which needs the use of siccative oil (linseed oil) as a mordant and a mineral charge composed of lead (lead white, litharge).

In our cases, under the silver or tin leaves, blue pigments have been often founded. This colour corresponds to the one of the background scene, independently of the presence of a gilding. The under-layer colour is not perceptible through these thick and opaque metallic leaves.

Under gold leaves, only red, yellow and more rarely white and black under-layers are applied (never blue). In ancient texts, a red or yellow bole is recommended to give more depth to the gilding and eventually to fill holes to the gold leaf.

\section{Sites and materials}

Gildings have been identified on mural paintings ( $14^{\text {th }}$ to $16^{\text {th }}$ century) in various sites in the Southwest of France (Aquitaine or MidiPyrénées regions), as the ancient convent in Oloron Sainte-Marie, the Bordeaux Cathedral, the Ste-Marie church (altarpiece) in Audignon and the Meyrals Castle.

An experimental study has been carried out, in order to understand the role of the underlayer:

- gold deposited on glass slides;

gilding reproductions made with different under-layers.

Gold was glued on red, black or white underlayers, with distemper and mixtion techniques. Seven types of gildings have been produced in the laboratory (denoted by PM1 to PM7), for a comparison with the stratigraphy found in samples taken from mediaeval sites. Gold and tin were used on red and blue layers using to the distemper and mixtion techniques on fresco (Figure 1). Red ochre and cinnabar were used for the red, and azurite for the blue colour.

These reproductions were submitted to a hygro-thermal and a UV ageing to observe alterations.

\section{Materials and Methods}

\section{Analytic methods}

Micro samples have been taken in UV fluo-
Correspondence: Aurélie Mounier, Centre de Recherche en Physique Appliquée à l'Archéologie - CRPAA, Institut de Recherche sur les Archéomatériaux - IRAMAT, UMR 5060, Université de Bordeaux/CNRS, 33607 Pessac, France.

Tel. +33.5.57.12.45.51 - Fax: +33.5.57.12.45.50.

E-mail: mounieraurelie33@yahoo.fr

Key words: mediaeval gildings, colour of underlayer, mixtion technique, thickness of metallic leaves.

Citation: Mounier A, Daniel F, 2013 The role of the under-layer in the coloured perception of gildings in mediaeval mural paintings. In: RH Tykot (ed.), Proceedings of the 38th International Symposium on Archaeometry - May 10th-14th 2010, Tampa, Florida. Open Journal of Archaeometry 1:e16.

Acknowledgements: this study is part of a project supported by the Aquitaine region. We thank the cultural institutions of Direction Régionale des Affaires Culturelles for their support and providing access to the various sites.

Presented at the $38^{\text {th }}$ International Symposium on Archaeometry - May $10^{\text {th }}-14^{\text {th }} 2010$, Tampa, Florida.

This work is licensed under a Creative Commons Attribution 3.0 License (by-nc 3.0).

(C)Copyright A. Mounier and F. Daniel, 2013 Licensee PAGEPress, Italy

Open Journal of Archaeometry 2013; 1:e16 doi:10.4081/arc.2013.e16

rescent zones, as fluorescence is generally due to the organic bindings used in ancient gildings (Mounier et al., 2011). Their examination was facilitated by an optical microscope and with a low-vacuum scanning electron microscope (SEM-LV) JEOL JSM 6460LV, coupled to an energy dispersive X-ray spectrometer (EDXS) Oxford INCA 300. The identification of pigments has been done by a Raman micro spectrometer, Renishaw RM 2000. The binder analyses have been carried out by infra-red spectroscopy (IRTF Nicolet Nexus), in attenuated total reflectance (ATR) mode. The optical absorption of the gold deposited on glass slides with an Emscope SC 500 metal coater, has been analyzed by UV-VIS absorption spectrophotometer (Varian CARY 1). Colour measurements (CIE D65, 10 ${ }^{\circ}$ ) have been made with a Konica Minolta spectrophotometer CM$2600 \mathrm{~d}$.

\section{Accelerated ageing}

UV accelerated ageing of the gilding reproductions (V313c) was carried out in an environmental chamber in order to irradiate them with UV B ( $=313 \mathrm{~nm}$ ) while maintaining them at a constant temperature of $45^{\circ} \mathrm{C}$ (QUV 
Accelerated Weathering Tester). The source irradiance was about $0.71 \mathrm{~W} / \mathrm{m}^{2}$ and the samples were located at a distance of about $4.5 \mathrm{~cm}$ imposed by the instrument's configuration. The exposure to UV lasted 400 hours (approximately 17 days in total).

Hygro-thermal ageing $\left(\mathrm{V}_{\mathrm{HT}}\right)$ was carried out in an environmental chamber (Vötsch VC 4018). The used protocol contains about eight hour cycles that include 4 phases of 90 minutes, with increase and decrease of the conditions, during 30 minutes between each cycle. These conditions are inspired by recent works on the pigments alteration on mural paintings (Aze, 2005). The different phases and temperature conditions and relative humidity are: i) strong humidity, with a temperature (T) of $18^{\circ} \mathrm{C}$ and a $85 \%$ relative humidity (RH); ii) low temperature: $\mathrm{T}=-10^{\circ} \mathrm{C}, \mathrm{RH}=0 \%$; iii) heat dry: $\mathrm{T}=40^{\circ} \mathrm{C}, \mathrm{RH}=25 \%$; iv) wet heat: $\mathrm{T}=30^{\circ} \mathrm{C}$, $\mathrm{RH}=60 \%$.

This cycle of $8 \mathrm{~h}$ was repeated 90 times for a total duration of 4 weeks ageing.

\section{Results and Discussion}

Four sites in the Southwest of France were chosen to illustrate the role and the variety of the under-layer colour.

\section{Saint-Andre cathedral of Bordeaux (14 ${ }^{\text {th }} \mathrm{c}$.), Arnaud de Puylehaut funerary wall paintings}

Gold and silver gildings are present on the upper register where God in glory is represented as a sun. Silver is localised on the sun and the Virgin crown (Mounier et al., 2009). The extremity of the shortest sunbeams ends with a gilded rose button. The sample stratigraphy taken on the rose button revealed three layers: on the wall, a red-orange layer composed of a mixture of calcite, red ochre and cinnabar; over, a thick layer of lead white mixed with an organic binder plays the role of an adhesive layer for the gold leaf.

In this example, the under-layer colour of the gold leaf appears white.

\section{Cordeliers convent of Oloron \\ Sainte-Marie $\left(14^{\text {th }} \mathrm{c}.\right)$, funerary wall paintings}

Remnants of polychromy and gildings were observed on a block discovered during the excavations of the ancient Cordeliers convent of Oloron Sainte-Marie [now conserved at the Service Régional d'Archéologie (Aquitaine region)]. The represented scene is a Virgin with a gilded veil, holding a wax candle. The sample stratigraphy resulting of the Virgin halo shows several layers: on the stone, a layer is composed of a calcite and red lead mixture; then a layer of calcite is applied and just under the gold leaf, a red ochre and calcite layer.

Most of samples from this block show that a red under-layer is applied under the gold leaf.

\section{La Roque Meyrals castle (15-16 c.), oratorical wall paintings}

In the oratory of the castle La Roque in Meyrals, gold gildings are visible on haloes (Daniel and Mounier, 2010). An orange or yellow under-layer is used under the gold leaves. In the Christ haloes, gold leaves are stucked by means of a lipidic binder on a layer composed of red lead and lead white. A carbon black layer is present in all samples. This black layer could be discovered according to the sgraffito technique (note that sgraffito technique consists of removing the gold leaf with a stylus to draw a pattern and let appear the under-layer) to simulate patterns on the haloes.

Audignon altarpiece $\left(15^{\text {th }} \mathrm{c}\right.$.), polychromed and gilded

On this altarpiece, the gold leaf is well preserved and visible in numerous places (haloes, crowns, clothes, jewels, keys, armors, ciborium, and pinnacles). On crowns, gold is glued with oil on a red under-layer composed of red lead and yellow ochre on a white support. On the prophet's brooch, a gold leaf is applied on a yellow under-layer (ochre) on a calcite and lead white layer as support. These examples show that a red, yellow, orange, white or black under-layer can be used under the gold leaf (Figure 2). In a same site, gold leaf could be applied on different coloured under-layers although warm colours seem to be preferred.

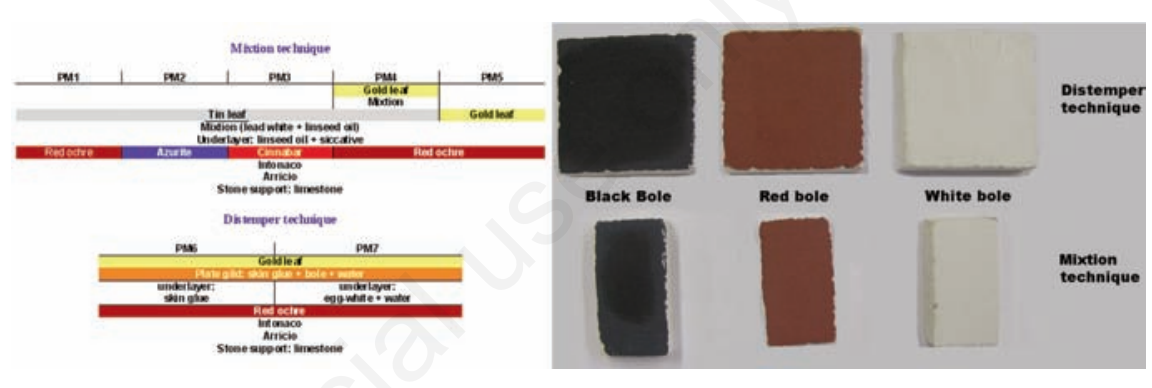

Figure 1. Seven types of gildings recreated to understand the role of the under layer of gold and tin leaves and to proceed on accelerated ageing. Three other recreations are made with a gold leaf to distemper and mixtion technique on black, red and white under layers.

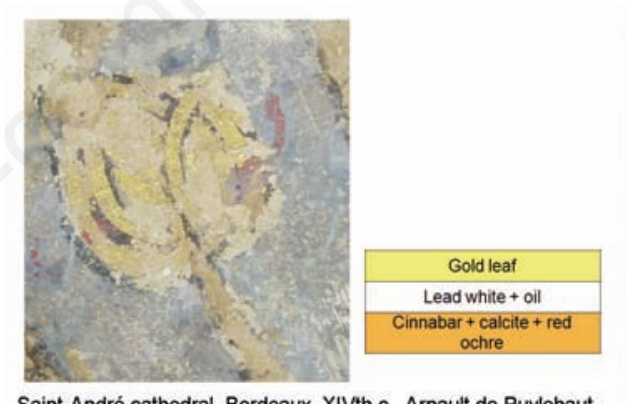

Saint-André cathedral, Bordeaux, XIVth c., Arnault de Puylehaut funeral paintings, rose button of the Christ glory scene

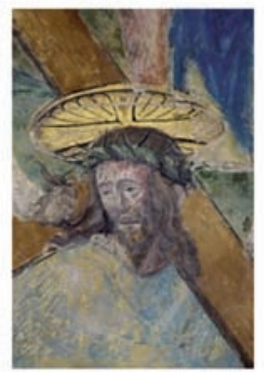

Oratory paintings of the Meyrals Castle, XVth c., cross portement, Christ halo

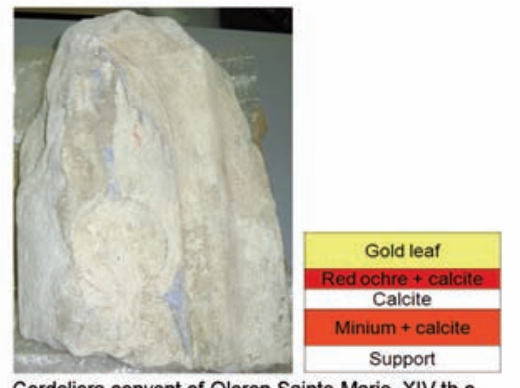

Cordeliers convent of Oloron Sainte-Marie, XIV th c., funeral paintings, Virgin halo.

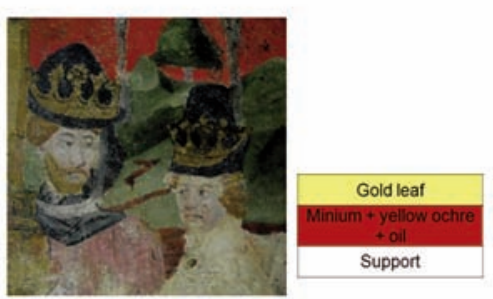

Audignon altarpiece, XVth c., childhood Christ scenes, kings witches crown

Figure 2. Examples of stratigraphic layers identified on the four sites. White, different red and orange were used under the gold leaf. Most of the time, two pigments were mixed for the coloured under-layer. 


\section{Experimental study}

Transmission spectra have been taken for different thickness of the gold deposited on glass blades. The maximal wavelength $(\max =516 \mathrm{~nm})$ value is the same for all spectra (Figure 3). Only the intensity and the transmittance change. The greenish colour transmitted through the gold leaf has to be compensated by a red (complementary colour) under-layer. The returned effect is a warm yellow colour, especially if the gold leaf suffered alterations (area thinner with a loss of gold).

Gilding reproductions on black, red and white under-layers (pigments + binders) have been made. These layers received a gold leaf

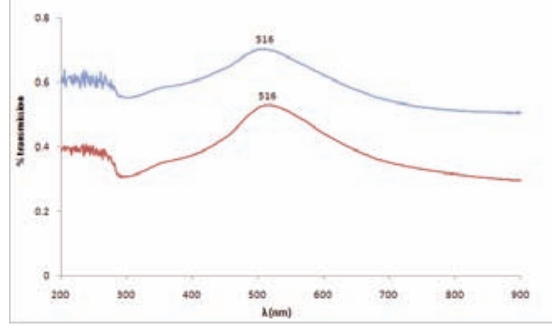

Figure 3. Transmission spectra of gold deposition during 30 seconds (blue curved) and 1 minute (in red).

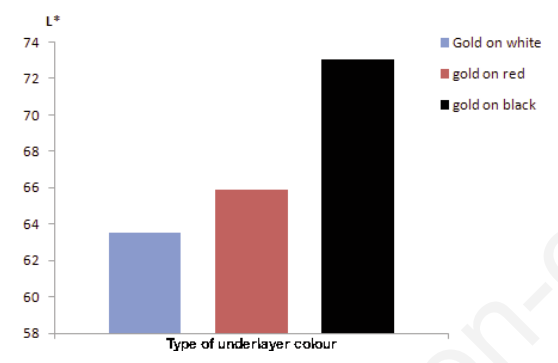

Figure 4. According to qualitative colorimetric measurements, in regards with the brightness, the gold leaf applied on a black under-layer seems to be shinier than the red or blue under-layers.

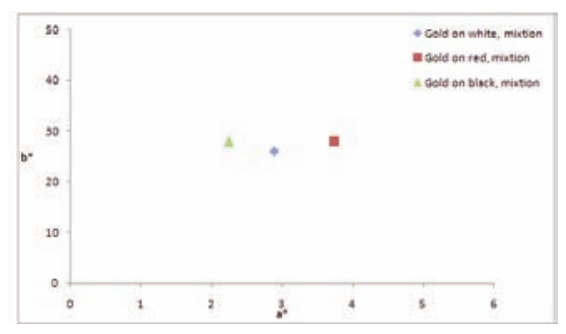

Figure 5. Gold leaf on a red under-layer tends towards red chromatics coordinates whereas gold on black bole, gold colour tends to black. The bole plays an important role on the gold colour perception. according to different techniques (mixtion or distemper). For each sample, chromatic coordinates in CIE $\mathrm{L}^{*} \mathrm{a}^{*} \mathrm{~b}^{*}$ colorimetric system have been measured (three points in five zones). Only the results obtained with the mixtion technique are presented here to compare with the in situ observations.

Obviously, the coloured nuances of the gold leaf depend on the colour of the under-layer (Figure 4). As brightness is concerned, the gold leaf could be shinier on a black bole than on a red or white bole (Figure 5). This explains that black under-layers have been sometimes found under gold leaves.

A study with similar results were obtained by Dumazet et al. (2007) regarding to the visual appearance of gold-gilded sculptures. The team proceeded to a sculpture reproduction gilded on colored layers: lead white, mixtures of red lead and cinnabar and an oil layer to stick the gold leaf $(24 \mathrm{~K}, 8 \times 8 \mathrm{~cm}, 200 \mathrm{~nm}$ thicknesses).

The spectrophotometry measures showed that a small fraction of light gets through the gold leaf and that it is selectively absorbed by the coloured under-layer. By the transmission spectra of the gold leaf, the indication of gold diffuse reflection was calculated thanks to the model of Kubelka-Munk [factor $\mathrm{K} / \mathrm{R}=(1$ $\mathrm{R} \infty)^{2} / 2 \mathrm{R} \infty$ ]. Colour measurements (CIE D65, $10^{\circ}$ ) in specular reflection were performed on some pure gold, some gold on black and on red bole. The role of the under-layer is important, particularly the size of the pigment grains in the under-layer which influences the gold leaf aspect. If the layer is granular or unrefined, the harshness is visible on the gold surface and the refraction phenomena might be complex.

The roughness of the metal leaf seems to modify the colorimetric data. Furthermore, the application of a gold leaf remains a delicate technique and according to zones, especially on sculptures and small zones, the gold leaf is folded or creased. This harshness is sharply visible and the light is not reflected in the same way. These phenomena will be stressed by holes and cracks of the gold leaf. The preservation, the ageing or the alteration of gold under-layers, also have an influence on the gilding perception. In every case, red allows to balance the gold gilding perception.

\section{Ageing of gilding reproductions}

Coloured measures show that the hygrothermal ageing modified the colour of the gilding. In comparison with our reference (unaged sample), the aged samples tend to turn yellow (b* axis), especially gold gilding recreations. The increase of $b^{*}$ is particularly sensitive for the PM4 and PM5, both realized with gold on mixtion technique. The colour difference is the most important $\left(\Delta \mathrm{E}^{*}>4\right)$ also for these two samples.
The positive moving of the chromatic coordinates in $\mathrm{b}^{*}$ axis denote a yellowing, more marked for PM4 and PM5 samples (gold leaf on mixtion), most probably due to the little mixtion layer yellowing (visually constated).

\section{Conclusions}

Often, on ancient gold gildings, only the under-layer which assures the adhesion of the metallic leaf is still visible. The colour of this under-layer, particularly under the gold leaf, is red, orange or yellow, rarely black or white. This under-layer plays a crucial role, as the UVVIS absorption spectrum by gold leaf gives to a yellow-green colour. To remove this greenish aspect, gold leaf is applied on a red under-layer.

Hygro-thermal ageing turns the gold leaf appearance yellow for the mixtion technique. Therefore, the under-layer colour associated with the binder used to agglomerate the pigments influence the gold perception mostly for aged gildings.

\section{References}

Aze S, 2005. [Altérations chromatiques des pigments au plomb dans les œuvres du patrimoine]. [PhD thesis in French]. Université d'Aix Marseille ed., Aix Marseille, 210 pp.

Cennini, $14^{\text {th }}$ century. [Il libro dell'arte]. [Book in Italian]. Re-ed. 1991. Berger-Levrault, Paris, pp 188-313.

Daniel F, Mounier A, 2010. Alteration of gilts on mediaeval mural paintings. In: ICOM CC (Interim Meeting) Meeting, Multidisciplinary conservation, a holistic view for historic interiors, Rome, 23-26 mars March 2010.

Dumazet S, Genty A, Zymla A, de Contencin F-X, Texier A, Ruscassier N, Bonnet B, Callet P, 2007. Influence of the substrate colour on the visual appearance of gilded sculptures. In: XXI International CIPA Symposium, 01-06 October, Athens, Greece.

Mounier A, Daniel F, Bechtel F, 2009. [L'illusion de l'or. Imitation de dorures dans les peintures murales médiévales]. [Article in French]. Archéoscience 33:397-403.

Mounier A, Dayet L, Belin C, Daniel F, 2011. [Etude de la fluorescence des liants employés dans les dorures sur peintures murales médiévales]. [Article in French]. Archéoscience 35:19-28.

Pline, $1^{\text {st }}$ century. [Histoire naturelle: nature des métaux]. [Book in French]. Re-ed. Zehnacker 1999. Les Belles Lettres, Paris.

Theophile, $12^{\text {th }}$ century. [Essais sur divers arts]. [Book in French]. Re-ed. Laget 1996. Cte Charles de l'Escalopier, Nogent Le Roi, pp 3944. 